\title{
A Patient With Focal Dystonia That Occurred Secondary to a Peripheral Neurogenic Tumor: A Case Report
}

\author{
Minho Park, MD, Hee-Sang Kim, MD, PhD, Jong Ha Lee, MD, PhD, \\ Dong Hwan Yun, MD, PhD, Jinmann Chon, MD, PhD, Yoo Jin Han, MD, PhD
}

Department of Physical Medicine and Rehabilitation, Kyung Hee University College of Medicine, Seoul, Korea

\begin{abstract}
Dystonia is a movement disorder characterized by involuntary muscle contractions. Patients with dystonia may experience uncontrollable twisting, repetitive movements, or abnormal posture. A 55-year-old man presented with an involuntary left forearm supination, which he had experienced for five years. There was no history of antecedent trauma to the wrist or elbow. Although conventional therapeutic modalities had been performed, the symptoms persisted. When he visited our hospital, electromyography was performed. Reduced conduction velocity was evident at the elbow-axilla segment of the left median nerve. We suspected that there was a problem on the median nerve between the elbow and the axilla. For this reason, we performed an ultrasonography and magnetic resonance imaging study. A spindle-shaped soft tissue mass was observed at the left median nerve that suggested the possibility of neurofibroma. Dystonia caused by traumatic or compressive peripheral nerve injury has often been reported, but focal dystonia due to a neurogenic tumor is extremely rare. Here, we report our case with a review of the literature.
\end{abstract}

Keywords Dystonia, Neurofibroma, Median neuropathy

\section{INTRODUCTION}

Dystonia is a movement disorder characterized by involuntary muscle contractions. Patients with dystonia may experience uncontrollable twisting, repetitive move-

Received August 4, 2014; Accepted October 13, 2014

Corresponding author: Hee-Sang Kim

Department of Physical Medicine and Rehabilitation, Kyung Hee University College of Medicine, 26 Kyungheedae-ro, Dongdaemun-gu, Seoul 130-701, Korea

Tel: +82-2-958-8565, Fax: +82-2-958-8560, E-mail: kimhsmd@khu.ac.kr

(c) This is an open-access article distributed under the terms of the Creative Commons Attribution Non-Commercial License (http://creativecommons. org/licenses/by-nc/4.0) which permits unrestricted noncommercial use distribution, and reproduction in any medium, provided the original work is properly cited.

Copyright () 2015 by Korean Academy of Rehabilitation Medicine ments, or abnormal posture. It is often initiated or worsened by voluntary action and associated with excessive muscle activation [1].

Dystonia caused by traumatic or compressive peripheral nerve injury has often been reported, but focal dystonia due to a neurogenic tumor is extremely rare. We encountered a case that demonstrated the association between a peripheral neurogenic tumor in a median nerve and focal hand dystonia. Here, we report our case and conduct a review of the literature.

\section{CASE REPORT}

A 55-year-old man presented at our medical facility with involuntary left forearm supination that he had ex- 
perienced for the past five years. The man, who is a university professor, felt discomfort when washing his face and typing on the keyboard (Fig. 1). He did not have a history of antecedent trauma to the wrist or elbow. There was no history of diabetes mellitus, thyroid disease and other medical problems, except that he was a hepatitis B carrier. In the neurology clinic in another hospital, delayed distal latencies at the left median nerve and ulnar nerve were apparent on a nerve conduction study (NCS). In addition, increased insertional activities were documented at the left flexor carpi radialis (FCR) and brachioradialis on a needle electromyography. A cervical magnetic resonance imaging (MRI) study showed disc space narrowing at C5-6 and multi-level disc protrusion (Fig. 2). Conventional therapeutic modalities, including ultra- sound, range of motion exercise and stretching exercise, were performed. Despite this, the symptoms persisted.

When the patient visited to our outpatient clinic, we conducted a physical examination of the patient. The dystonia mainly involved his left forearm, was present at rest, and became more marked with activity such as typing or washing. No trunk, face and lower extremity dystonia was observed. On the manual muscle test, both upper extremities showed Medical Research Council (MRC) grade 5 power, and superficial sensory impairment were assessed by a pinprick and light touch test, he felt the same in both upper extremities and the face. Tactile spatial acuity was assessed by a two-point discrimination (2PD) test on the forearm. The threshold of a 2PD test in the unaffected arm was about $8 \mathrm{~mm}$, but about $10 \mathrm{~mm}$ in
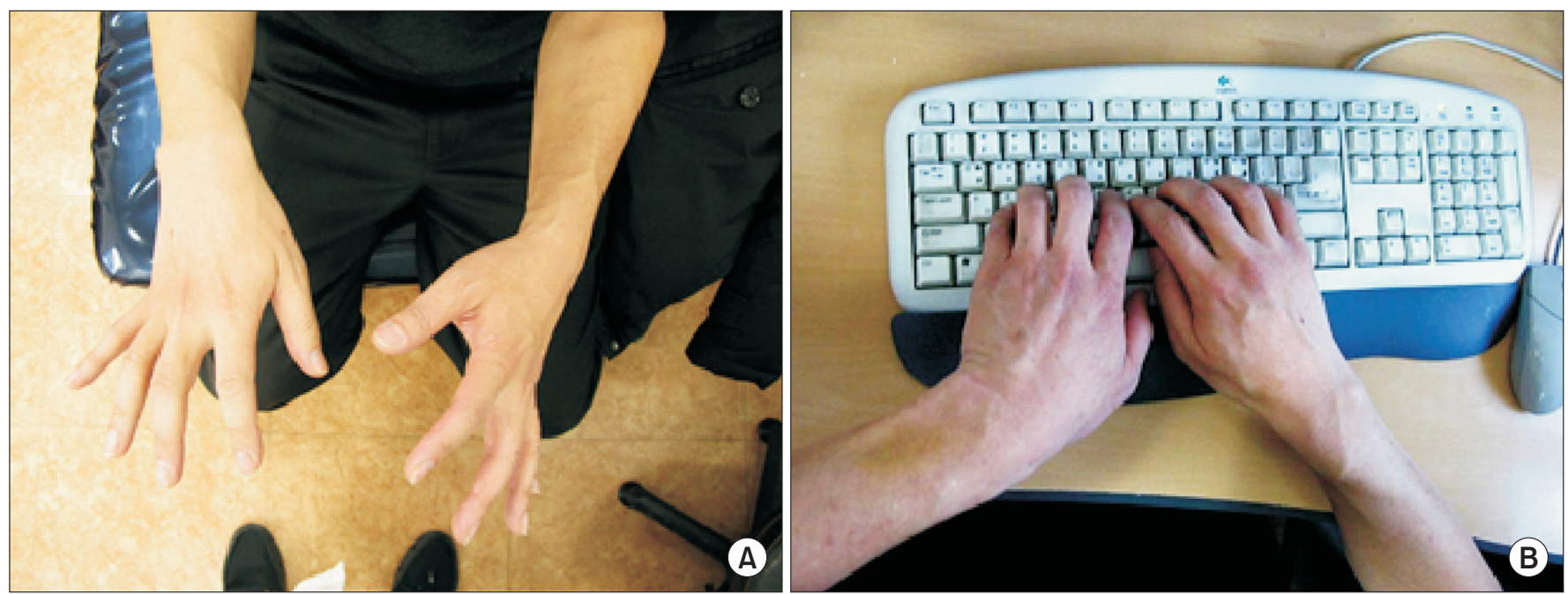

Fig. 1. Clinical presentation. (A) Involuntary forearm supination with elbow flexed at $90^{\circ}$. (B) He had to type on a keyboard by raising his elbow due to forearm supination.
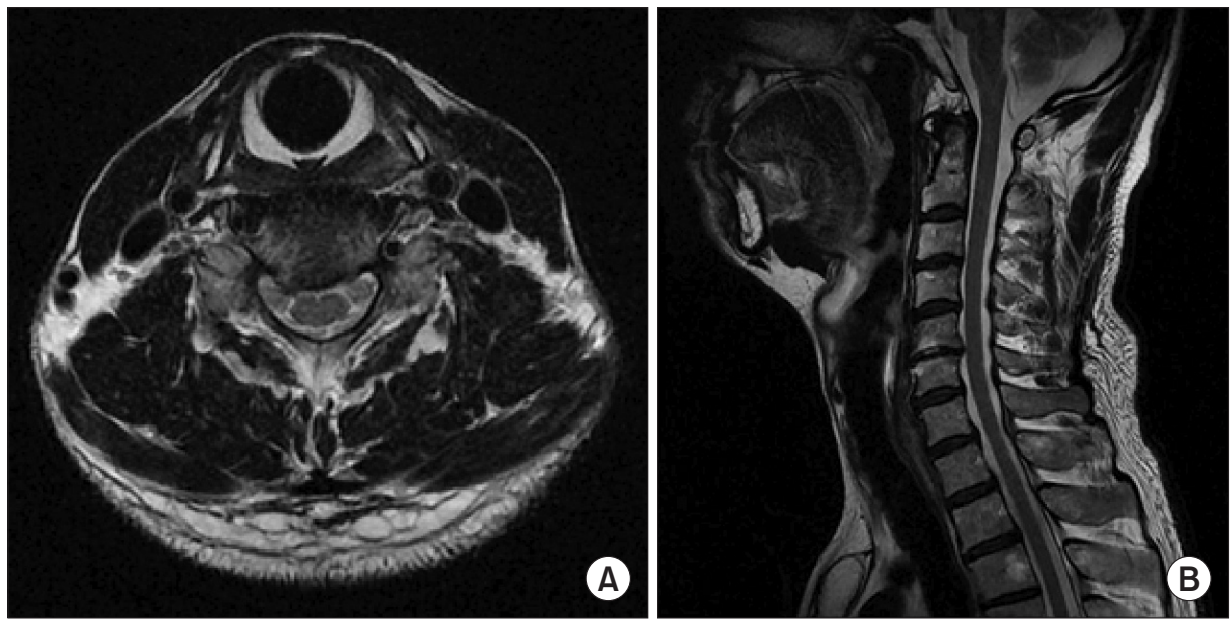

Fig. 2. Cervical magnetic resonance image taken at another hospital. (A) Sagittal image demonstrates disc space narrowing at C5-6 and multi-level disc protrusion. (B) Axial image demonstrates right paracentral disc protrusion at C5-6 level. 
Minho Park, et al.

Table 1. Results of motor nerve conduction study

\begin{tabular}{|c|c|c|c|}
\hline Nerve/Sites & Latency (ms) & Amp 1-2 (mV) & Velocity $(\mathrm{m} / \mathrm{s})$ \\
\hline \multicolumn{4}{|c|}{ R. Median - recorded at APB } \\
\hline Wrist & 3.35 & 14.2 & - \\
\hline Elbow & 7.50 & 14.3 & 54.2 \\
\hline Axilla & 9.95 & 14.7 & 63.3 \\
\hline $\mathrm{EP}$ & 13.55 & 13.3 & - \\
\hline \multicolumn{4}{|c|}{ L. Median - recorded at APB } \\
\hline Wrist & 3.85 & 11.1 & - \\
\hline Elbow & 8.25 & 11.0 & 53.4 \\
\hline Axilla & 10.50 & 11.4 & 48.9 \\
\hline $\mathrm{EP}$ & 14.65 & 11.3 & - \\
\hline \multicolumn{4}{|c|}{ L. Ulnar - recorded at ADM } \\
\hline Wrist & 2.70 & 11.3 & - \\
\hline Elbow & 7.35 & 10.1 & 60.2 \\
\hline \multicolumn{4}{|l|}{ L. Radial - recorded at EIP } \\
\hline Forearm & 2.20 & 7.2 & - \\
\hline Elbow & 5.05 & 6.4 & 59.6 \\
\hline Arm & 6.15 & 6.2 & 63.6 \\
\hline \multicolumn{4}{|l|}{ R. Radial - recorded at EIP } \\
\hline Forearm & 2.25 & 7.9 & - \\
\hline Elbow & 4.85 & 7.5 & 63.5 \\
\hline Arm & 6.00 & 7.2 & 69.6 \\
\hline
\end{tabular}

APB, abductor pollicis brevis; EP, Erb's point; ADM, abductor digiti minimi; EIP, extensor indicis proprius; L., left; R., right.

Table 2. Results of needle electromyography

\begin{tabular}{|c|c|c|c|c|c|c|c|c|}
\hline \multirow{2}{*}{ Muscle } & \multicolumn{4}{|c|}{ Spontaneous Activity } & \multicolumn{3}{|c|}{ MUAP } & \multirow{2}{*}{$\begin{array}{c}\text { Recruitmen } \\
\text { pattern }\end{array}$} \\
\hline & IA & Fib & PSW & Others & Amp & Dur & PPP & \\
\hline L. APB & $\mathrm{N}$ & None & None & None & $\mathrm{N}$ & $\mathrm{N}$ & $\mathrm{N}$ & $\mathrm{N}$ \\
\hline L. Pron Quad & $\mathrm{N}$ & None & None & None & $\mathrm{N}$ & $\mathrm{N}$ & $\mathrm{N}$ & $\mathrm{N}$ \\
\hline L. ADM & $\mathrm{N}$ & None & None & None & $\mathrm{N}$ & $\mathrm{N}$ & $\mathrm{N}$ & $\mathrm{N}$ \\
\hline L. FCR & $\mathrm{N}$ & None & None & None & $\mathrm{N}$ & $\mathrm{N}$ & $\mathrm{N}$ & $\mathrm{N}$ \\
\hline L. FCU & $\mathrm{N}$ & None & None & None & $\mathrm{N}$ & $\mathrm{N}$ & $\mathrm{N}$ & $\mathrm{N}$ \\
\hline L. Pron Teres & $\mathrm{N}$ & None & None & None & $\mathrm{N}$ & $\mathrm{N}$ & $\mathrm{N}$ & $\mathrm{N}$ \\
\hline L. FPL & $\mathrm{N}$ & None & None & None & $\mathrm{N}$ & $\mathrm{N}$ & $\mathrm{N}$ & $\mathrm{N}$ \\
\hline L. ECR & $\mathrm{N}$ & None & None & None & $\mathrm{N}$ & $\mathrm{N}$ & $\mathrm{N}$ & $\mathrm{N}$ \\
\hline L. EIP & $\mathrm{N}$ & None & None & None & $\mathrm{N}$ & $\mathrm{N}$ & $\mathrm{N}$ & $\mathrm{N}$ \\
\hline L. Supinator & $\mathrm{N}$ & None & None & None & $\mathrm{N}$ & $\mathrm{N}$ & $\mathrm{N}$ & $\mathrm{N}$ \\
\hline L. Biceps & $\mathrm{N}$ & None & None & None & $\mathrm{N}$ & $\mathrm{N}$ & $\mathrm{N}$ & $\mathrm{N}$ \\
\hline L. Triceps & $\mathrm{N}$ & None & None & None & $\mathrm{N}$ & $\mathrm{N}$ & $\mathrm{N}$ & $\mathrm{N}$ \\
\hline L. C PSP (C6-7) & $\mathrm{N}$ & None & None & None & & & & \\
\hline
\end{tabular}

MUAP, motor unit action potential; IA, insertional activity; Fib, fibrillation; PSW, positive sharp wave; Amp, amplitude; Dur, duration; PPP, polyphasic potential; APB, abductor pollicis brevis; Pron Quad, pronator quadratus; ADM, abductor digiti minimi; FCR, flexor carpi radialis; FCU, flexor carpi ulnaris; Pron Teres, pronator teres; FPL, flexor pollicis longus; ECR, extensor carpi radialis; EIP, extensor indicis proprius; C PSP, cervical paraspinal; N, normal; L., left. 

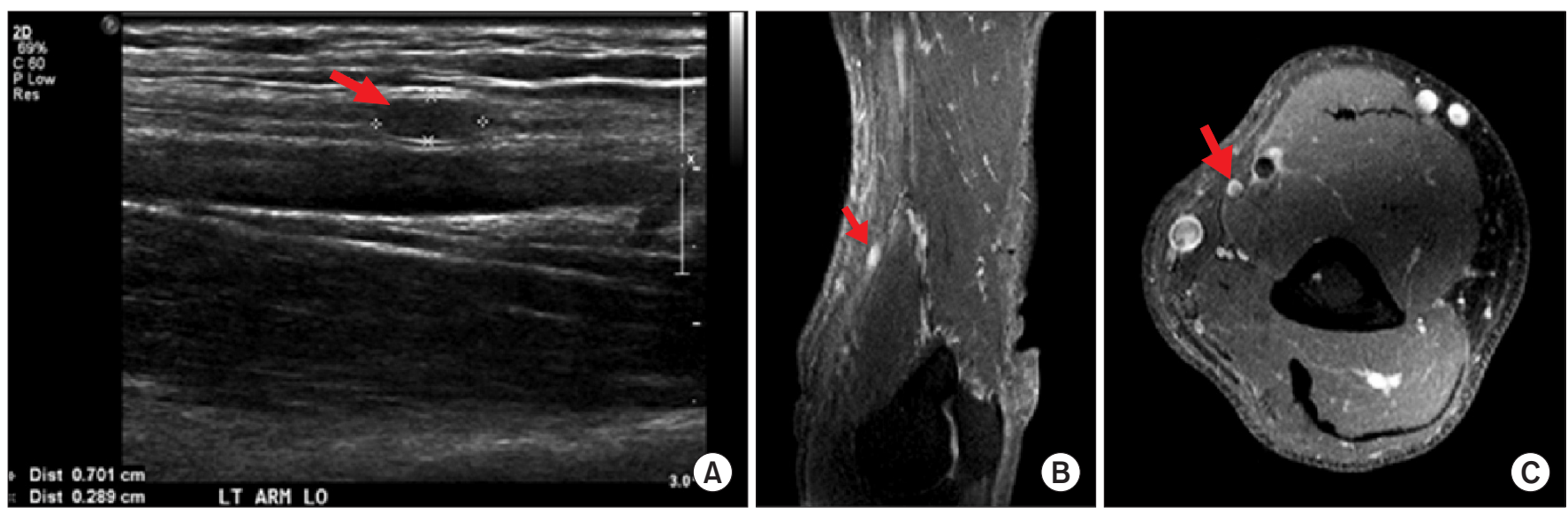

Fig. 3. Imaging study of left upper extremity. (A) Longitudinal ultrasonographic scan of distal arm demonstrates nodular shaped mass in the median nerve. (B) T1 sagittal image with gadolinium enhancement demonstrates a high signal nodular lesion at the distal arm. (C) T1 transverse image with gadolinium enhancement demonstrates a high signal target appearance mass in the median nerve at the distal arm.

the affected arm.

The deep tendon reflex was normal and Tinel sign at the wrist and elbow was not present. Spurling test showed a negative finding.

Electrodiagnostic studies were conducted once again to more clearly delineate the problem. The sensory NCS was relatively normal but the motor NCS revealed decreased conduction velocity at the elbow-axilla segment of the left median nerve (Table 1). There was no abnormal spontaneous activity and the needle electromyography showed that the recruitment of the motor unit action potential was normal (Table 2). Based on electrophysiologic findings, which indicated left median neuropathy above the elbow, we suspected that there was a problem on the median nerve between the elbow and axilla. First, ultrasonography was performed on the left upper extremity, and there was a $7 \times 5 \times 5-\mathrm{mm}$ nodule in the median nerve at the distal arm. A left upper extremity contrast-enhanced MRI was performed to evaluate the soft tissue mass more accurately. In the MRI examination, a spindle-shaped soft tissue mass was observed at the left median nerve that suggested the possibility of neurofibroma or schwannoma (Fig. 3). We recommended surgical mass excision. However, the patient refused to undergo surgery because of potential side effects, such as paralysis. In order to treat dystonia, conventional treatments were administered, but the symptoms only improved temporarily.

\section{DISCUSSION}

Dystonia is a movement disorder that manifests with various clinical features. It is classified according to the age of onset, body distribution, temporal pattern, associated features or etiology [1]. Among them, focal dystonia is a type of dystonia involving a single region of the body. Focal dystonia might occur idiopathically (primary dystonia) or secondary to an abnormality in the central or peripheral nervous system (secondary dystonia). Secondary focal dystonia after trauma manifests as 'fixed dystonia' unlike primary focal dystonia [2]. A well-known type of focal dystonia is task-specific (action) dystonia, such as writer's cramp, typist's dystonia, or musician's dystonia. Mostly these types of task-specific dystonia have no evidence of degeneration or structural lesions.

To date, the pathophysiology of dystonia has been researched, but we know little about it. The previous pathophysiological study focused on motor pathways.

Iyer and Thirkannad [3] suggested that peripheral nerve injury could potentially influence the motor control circuit leading to dystonia. Quartarone et al. [4] suggested that abnormal sensorimotor plasticity contributed to dystonic movements by using a paired associative stimulation technique. These maladaptive tendencies occurred as a result of environmental factors such as peripheral nerve trauma or injury that was intrinsically genetic.

Although dystonia is a movement-related disease, se- 
veral recent research reports have suggested that the sensory system plays a major role in dystonia. Electrophysiological evidence supports this opinion using somatosensory evoked potential [5]. Furthermore, spatial somatosensory dysfunction contributes to dystonia [6].

In addition, various experimental studies were performed to reveal the association between sensory dysfunction and dystonia.

There are several important points in this case. Firstly, this case showed focal dystonia that occurred secondary to a peripheral neurogenic tumor. To the best of our knowledge, this is first case of focal dystonia secondary to peripheral neurogenic tumor, which has been demonstrated electrophysiologically and clinically. Furthermore, most cases have reported dystonia associated with ulnar nerve injury, but this case has dealt with problems on the median nerve, which is rare. Secondly, it is not difficult to find the electrophysiologic abnormality in previous reported cases. However, we paid great attention to detail when interpreting the electrophysiologic study. As a result, we found subtle electrophysiological changes.

Because of these subtle changes in the electrodiagnostic study, we suspected a lesion above the elbow. Therefore, imaging studies were performed, and we discovered a neurogenic tumor in the median nerve. There is an implication that the peripheral neurogenic tumor can potentially cause changes in sensorimotor control circuits leading to focal dystonia.

It is unusual to encounter a patient with dystonia. However, when we evaluate a patient with dystonia, peripheral nerve disorders, such as peripheral nerve tumors should be suspected, if the findings of other tests have been normal.

\section{CONFLICT OF INTEREST}

No potential conflict of interest relevant to this article was reported.

\section{REFERENCES}

1. Albanese A, Bhatia K, Bressman SB, Delong MR, Fahn $S$, Fung VS, et al. Phenomenology and classification of dystonia: a consensus update. Mov Disord 2013; 28:863-73.

2. Jankovic J. Peripherally induced movement disorders. Neurol Clin 2009;27:821-32.

3. Iyer V, Thirkannad S. Focal hand dystonia in a patient with ulnar nerve neuropathy at the elbow. Hand 2010;5:453-7.

4. Quartarone A, Morgante F, Sant'angelo A, Rizzo V, Bagnato $\mathrm{S}$, Terranova $\mathrm{C}$, et al. Abnormal plasticity of sensorimotor circuits extends beyond the affected body part in focal dystonia. J Neurol Neurosurg Psychiatry 2008;79:985-90.

5. Tamura Y, Matsuhashi M, Lin P, Ou B, Vorbach S, Kakigi R, Hallett M. Impaired intracortical inhibition in the primary somatosensory cortex in focal hand dystonia. Mov Disord 2008;23:558-65.

6. Bara-Jimenez W, Shelton P, Hallett M. Spatial discrimination is abnormal in focal hand dystonia. Neurology 2000;55:1869-73. 